Article

\title{
Development of an Improved Solid Waste Collection System using Smart Sensors
}

\author{
Promise Elechi ${ }^{1}{ }^{*}$, Sunny Orike ${ }^{2}$, Augusta Ogonda Igbudu ${ }^{1}$ \\ ${ }^{1}$ Department of Electrical/Electronic Engineering, Rivers State University, Port Harcourt, Nigeria \\ ${ }^{2}$ Department of Computer Engineering, Rivers State University. Port Harcourt, Nigeria \\ *Correspondence: elechi.promise@ust.edu.ng
}

How to cite this paper: Elechi, P., Orike, S., \& Ogonda Igbudu, A. (2021). Development of an Improved Solid Waste Collection System using Smart Sensors. World Journal of Electrical and Electronic Engineering, 1(1), 51-65. Retrieved from

https://www.scipublica-

tions.com/journal/in-

dex.php/wjeee/article/view/151

Received: September 20, 2021

Accepted: October 27, 2021

Published: October 28, 2021

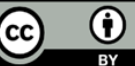

Copyright: ๑) 2021 by the authors. Submitted for possible open access publication under the terms and conditions of the Creative Commons Attribution (CC BY) license (http://creativecommons.org/licenses /by/4.0/).

\begin{abstract}
Waste collection system has become a challenging task, occasioned by the overflowing garbage bins littered all over the environment, causing environmental hazard and further leading to incurable diseases which endanger life. The present-day waste collection system has proven to be inefficient, taking into consideration the advancement in the technologies on the rise in recent years as well as the continuous increase in population growth. As a result of this inefficiency observed, this work developed a model for electronic waste collection system in a telecommunication driven environment. In the system's implementation, PIC18F4620 based instrumentation, integrated with proximity sensor for external monitoring and level sensors for internal monitoring was adopted, while the controlling of the opening and closing of the cabins was implemented using a smart switching board. A remote reporting to the waste management authority so as to systematically plan route-map for garbage collection when the waste cabin is fully filled was done by deploying a $900 \mathrm{MHz}$ transmitter interfaced with the system's controller. The result shows that with this model the waste cabin opens only on account of a user approaching the sensing distance of the system and the cabin is not filled. But when the cabin gets filled and a user approaches the sensing distance of the system, it directs the user to use the nearest waste cabin by displaying a message on the LCD (Liquid Crystal Display), while communicating with relevant authority for the evacuation of the cabin via SMS. It was obviously seen that the automation incorporated into the system had zero impact on the success rate of the system or system availability while introducing a latency of 5.6 seconds, which is just $28.0 \%$ of the maximum allowable latency of this kind of system, while protecting the environment from environmental pollution and spread of diseases. This work highlights the potentials of (EWCS) Electronic Waste Collection System in monitoring and controlling waste disposal for healthy and clean environment.
\end{abstract}

Keywords: Waste Collection, Transmitter, Sensor, Controlling

\section{Introduction}

\subsection{Background of the Study}

Solid waste which is the main cause of environmental pollution, has been defined under Resource Conservation and Recovery Act as any solid, semisolid or contained gaseous material from agricultural, commercial, mining or industrial operations and from community activities, be it locally or globally, waste control is a continuously increasing problem as population increases [1]. Solid wastes arise mainly from the activities of humans and animals. In general terminology, solid wastes can be defined as the organic and inorganic waste materials produced by various activities of the society and which have lost their value to the first user. 
The day-to-day domestic waste is collected as a whole, by placing a dustbin at a particular place either in lanes or streets [2]. The process of checking the status of the bin is the toughest part. In the existing method, the municipal worker has to look through all the different areas where the bins are placed in order to collect the waste. This is a tiring and a time-consuming task. The existing method of the waste control system is considerably inefficient, when the current development in technology is taken into consideration. There is no guarantee that the waste management worker(s) will be at the right place as well as the right time to collect the waste. In order to overcome the problems faced due to the existing method, a new way of approaching the waste control system automatically is proposed. It is the leap taken in the direction of automating the waste management to make it more efficient [3]. A recent advancement in the technology has enhanced the connection of everything via the Internet, using internet, it is possible to build an intranet and coordinate all the bins there by having a centralized system [4].

Electronics waste control system designed here is to implement a smarter way of conventional waste control using smart sensors to sense the presence of human around the waste bin, monitor the garbage level within the waste bin and relays information as regards the filled level status of the waste cabin to the waste control authority. The data acquired as above, can be used to systematically plan route-map to collect garbage. The information from the waste bins to the configured number at waste control office is sent using a communicating module (GSM module). The entire operation is controlled using a microcontroller [5].

\subsection{Statement of the Problem}

Convectional waste control system which is currently deployed in Nigeria has static routes and schedules where garbage from waste bins is collected on fixed schedules, regardless if the bins are full or not. Most times the waste bins are filled and the garbage spreads on open streets, thereby severely affecting the health and hygiene of the people. However, with the adoption of an improved waste collection system using proximity sensors, microcontroller and GSM module, the above problem is taking care of, and by this means, the waste control authority can effectively handle the waste disposal problem of the society without stress and at a very low cost as relevant information will be relayed by the system to them concerning system's state. This significantly, will improve the healthy state of the environment.

The aim of this project was to improve on the operation of a solid waste collection system using proximity sensors, microcontroller, and GSM module.

\subsection{Review of Related Works}

Srikanth et al. (2017)[6] carried out a work on overview for solid waste bin monitoring and collection system. The technologies used in the work are Radio Frequency Identification (RFID), Global Position System (GPS), General Packet Radio Service (GPRS), Geographical Information System (GIS) and web camera. The collection trucks are embedded with RFID reader which helps in retrieving all the customers as well as the bin information from the RFID tags placed in each bin. The locations of the bins are giving by GPS. Authentication by the use of driver id is needed to start the collection session. The waste disposal trucks with the help of RFID reader picks up the RFID tagged bins. The RFID tags are the keys for retrieving the information stored in the back-end database.

In RFID for the business of waste control, a similar work was carried out "Smart Garbage Collection System in Residential Area". The work is based on a concept that includes a camera being mounted on each garbage collection marker as well as a load sensor fitted at the bottom of the trash bin. The camera is used to take regular snapshots of the trash bin. The camera and the load sensors are set with a threshold value so that they can be compared. A microcontroller is used to perform the comparison. An idea about the garbage level can be conceived by performing image analysis and the weight of garbage can 
be evaluated by using the load sensor. The threshold level of the trash bin is checked by the controller. The controller, with the help of GSM module, sends a message to the local central office of the garbage collection unit so that it can notify that the garbage needs to be collected. Due to this, the authorities send the garbage collecting vehicle to dispose the wastes, which is performed by implementing a robot mechanism.

[7] designed a smart waste control with self-describing object. This work was based on the concept of associating smart waste control with digital information. The digital information which is associated to a waste can be stored within a QR code or a RFID tag memory. If the QR codes are used, the objects are needed to be in the line of sight. In the case of RFID technology, the information in the RFID tags can be retrieved without requiring the object to be in a particular position during the operation. Nowadays, the UHF tags are being used in the area of supply chain management since the data can be read easily within a distance of five meters from the antenna of the reader. This UHF tag-based concept uses the memory of the tags to store the information in data banks memory. This tag memory is used to store the digital information of the associated waste. The smart waste system requires only RFID reader to read the data. The work also proposes a classification system of the wastes. According to this proposal, a particular type of waste is allocated to a unique identification number. The classification is used to store the reference number which represents the waste type in the memory of each tag connected to each type of waste.

[8] designed an approach for monitoring and smart planning of urban solid waste control using smart-M3 platform. This work was based on a waste management system which has a bin in which there are two types of sensors: a proximity sensor located on the upper part of the bin and a weight sensor located in the bottom of the bin. The proximity sensor is used to measure the level of the wastes in the bin and the weight sensor is used to find the weight of the wastes present in the bin. Every bin has a ZigBee module installed which will be able to measure the physical quantities to the nearest light pole. The gateway of the system is implemented by a Raspberry PI which is used to collect process and transmit the data measured by the two sensors to the central control center. The control center uses the data retrieved by the sensors to implement efficient and effective optimization strategies as well as to find solutions for problems based on organization of resources on solid waste control. The control center is also responsible to inform any vehicle whether and when the bin is empty or full.

Another related work was done by [9]. RFID-Based Real-Time Smart Waste Collection System. This work is based on a system which proposed a RFID based waste collection system. This proposed system consists of a smart waste RFID tag, a RFID Reader as well as a Waste Control IT System (WCITS). A passive unique RFID tag is used in this system since passive tags do not require battery. These tags are powered by the RFID Reader and have a read range of about 10 meters. The antenna in the RFID Reader picks up the radio waves. The RFID Reader is attached to the Personal Digital Assistant (PDA) and the unique identification number of the bin is displayed. The PDA is installed in the garbage collecting vehicle. The waste collector truck consists of a robotic arm and the weighing system is present in the arm. The weight of the bin can be determined by the help of load sensors present in the weighing system. The Bin ID is used in the calculation of waste disposal charges of individual houses and the result is stored in a temporary storage in the PDA. At the end of the work shift, all the data is stored in a SQL back-end server for storage and processing of information. This data transfer is implemented by using Wi-Fi connection and the internet.

\section{Materials and Method}

\subsection{Materials}

The materials used in the implementation of this work are: 
1. PIC 18F4520 Microcontroller

2. $16 \times 2$ Alphanumeric LCD (LMO16L)

3. GSM Module (SM 900A)

4. PIR Sensor

5. LDR (Light Dependent Resistor)

6. LED (light emitting diode)

7. LM 358 OP AMP

8. DC Motor

9. Relay

10. ULN 2003A

11. Resistor (10k)

12. $5 \mathrm{~V}$ voltage regulator

13. Capacitor $(2200 \mathrm{uF}, 15 \mathrm{pF})$

14. Bridge Rectifier

15. 12VOLTS 2AMPS Transformer

16. Variable Resistor

\subsection{Methods}

Following the standard systematic approach for engineering design and implementation for proper and reliable solid waste collection system design in accordance with its aim and objective, series of effectual and adequate steps were followed. The end output of one step serves as the basic stand of the next proceeding step beginning according to hierarchical order. The project was carried out using the following design steps;

- Design consideration

- Power specification

- Physical structure

- Circuit design

- Component interfacing and simulation

\subsubsection{Design Consideration:}

The very first step of every project is to determine the exact requirements of the individual parts of the system, this in general enables the system designer to have a concrete idea on what the system is required to achieve at the end and also enable the designer to have a standard of measurement of how much of the specified qualities of the system is achieved at the end of the system design.

\subsubsection{Power Specification}

The design and functionality of this project requires the use of two DC power supplies, a 5 Vdc power supply and a 12 Vdc power supply. The sensors, GSM Module, LCD display, LM358, ULN2003A, relays and the microcontroller require a 5 Vdc power supply while the DC motor that will wheel up the waste bin cover required a $12 \mathrm{Vdc}$ power supply. 


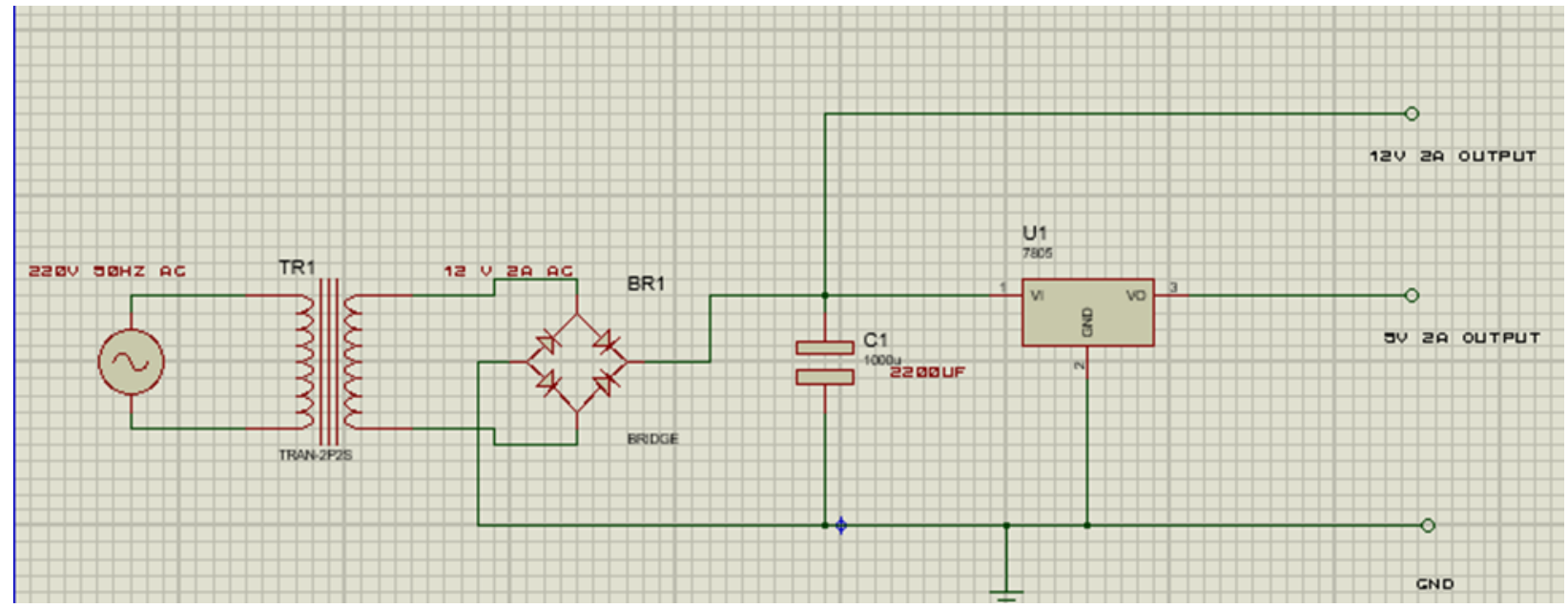

Figure 1. Power Supply

The power supply in Figure 1 shows the $220 \mathrm{~V}$ source directly transformed to a $12 \mathrm{~V}$ $\mathrm{AC}$ by the transformer, the transformed output is rectified to equivalently 11.6 volts which is then filtered and regulated by the capacitor and regulator respectively. The LM7805 was used to obtain 5V DC output for the sensors, relay, drivers and the GSM module and a direct 12V DC was used to power only the DC motor. The PIC 18F4520 Microcontroller is supplied with 5V DC because it doesn't have an internal regulator of its own. The calculation to obtain the capacitor value for the filtration using $Q=C V$.

\subsubsection{Circuit Design}

This part describes the individual electronic components that came together to make up the entire system. This starts with the block diagram of the system, which illustrates how the individual subsystems ties up together to form the entire system. It is as shown in the Figure 2.

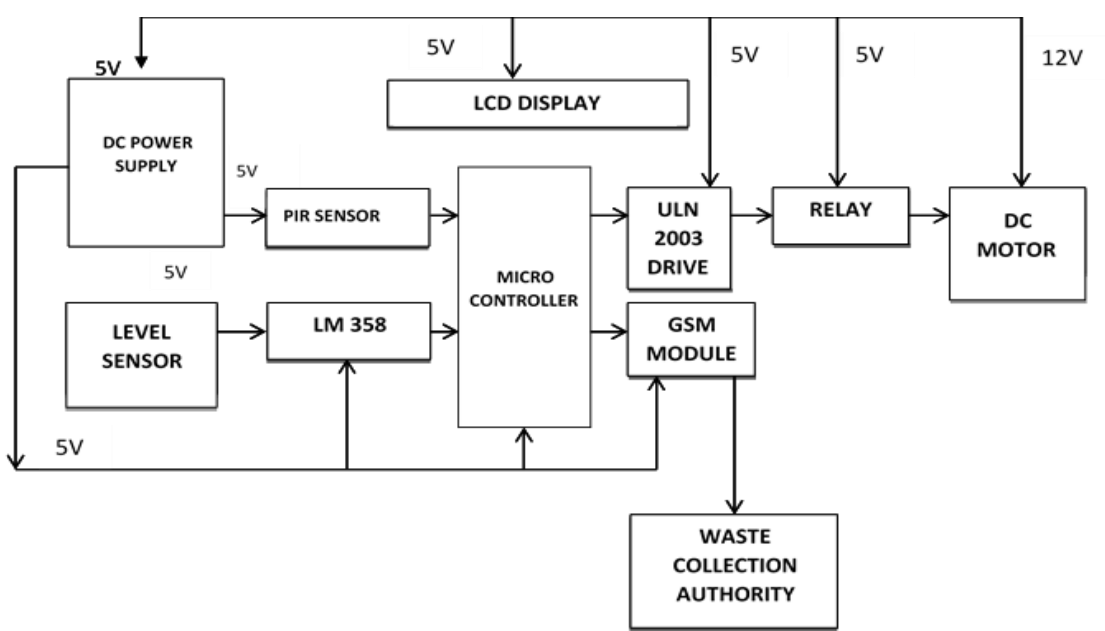

Figure 2. Block Diagram of a Solid Waste Collection System.

Figure 2 shows the interconnection of the units that makes up the smart solid waste collection system. It consists of two power supply units, $5 \mathrm{~V}$ DC power supply and $12 \mathrm{~V}$ DC power supply. The power supply unit of 5V DC supplies voltage to the microcontroller, the level sensor, PIR sensor, GSM modem, LCD display, ULN 2003 driver, LM 358 and the relay, while the $12 \mathrm{~V}$ power supply supplies voltage to the DC motor that wheels up the waste bin cover. When someone comes closer (predefined sensing distance) to the 
waste bin to dispose waste, the PIR sensor senses the person and immediately signals the microcontroller. The microcontroller on receiving the signal activates the DC motor by sending a HIGH state signal to the ULN2003 driver that drives the relays which eventually activates the DC motor. The DC motor then wheels up the waste bin cover. After disposal, the waste bin closes back through the help of the DC motor as well. After the closure, the microcontroller deactivates the ULN2003 driver by sending a LOW state signal to it which then de-energizes the relay and in turn deactivates the DC motor. The level sensor monitors the level of waste in the waste bin. The LDR, LED and LM358 are the three main components that act as the level sensor. The LDR and LED are placed directly opposite each other in the waste container, its designed in such a way that Light rays coming from the LED will constantly fall on the LDR surface, so when the waste disposed in the container reaches a level that it begins to block the light rays from getting to the LDR, this signifies that the waste bin is full, then the LM 358 OPAMP will detect a voltage drop at the LDR as a result of reduced light intensity. After this detection the OPAMP will send a high state to the microcontroller which then activates the GSM module to communicate the waste control authority concerning the fill level of the waste bin. Upon activation of the GSM module, the microcontroller will write to the LCD to display the status fill information on the display panel after which the PIR sensor will receive a low state from the microcontroller disconnecting it from the circuit until the entire system is being RESET manually on arrival of the municipal workers. The signal transmitted by the GSM Module is received as text message at the local base station. After receiving the signal, the local base station decodes the waste bin location and accordingly sends a dispatch signal to the nearest monitoring vehicular system about the location of the waste bin for immediate pickup of trashes in the waste.

\subsubsection{Proximity Sensor and Microcontroller}

The proximity sensor used in this project is the PIR sensor. It is interfaced to the microcontroller by connecting it directly to the pin 23(RC4/SD1/SDA) of the microcontroller. The PIR sensor is mounted on the body of the waste bin so that it can be able to detect when someone is coming towards the waste bin to drop waste. When the presence of a human is detected, the PIR sensor will send a high state signal to the microcontroller. The microcontroller will in turn send a high state to the ULN 2003A driver that will energize the relay to trigger on the DC motor so that the container can be wheeled open. Figure 3 shows the schematic of how the PIR sensor was interfaced with the microcontroller.

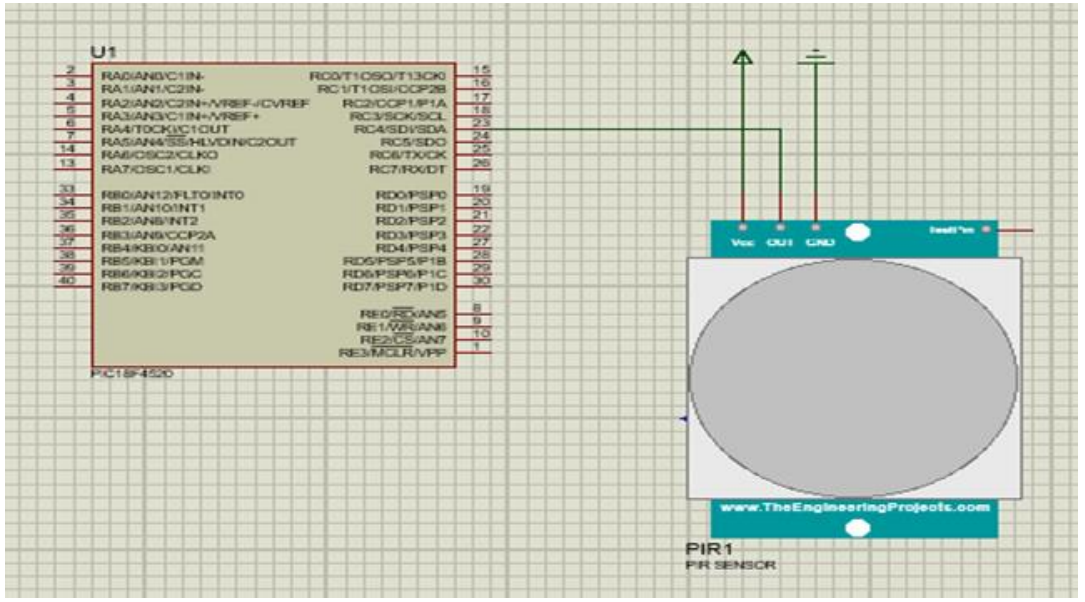

Figure 3. Schematic Diagram Showing the PIR Sensor Interfaced to the Microcontroller. 


\subsubsection{Motor and Microcontroller}

The major function of the DC motor in this project is to wheel up the top cover of the waste bin on detection of human presence by the PIR sensor. The DC motor is interfaced with the microcontroller in such a way that it is being driven by a 5V relay and ULN2003A driver. The ULN2003A driver is made up of seven Darlington paired NPN transistors fabricated into one chip, this driver is connected to pin 15(RC2) and pin 16(RC1) of the microcontroller. On sensing a high state signal from the microcontroller, the ULN2003A driver will give a low output that will energize the $5 \mathrm{~V}$ relay which in turn triggers the $12 \mathrm{~V}$ DC motor. Figure 4 is the schematic diagram showing the interfaced sections of the microcontroller and the DC motor.

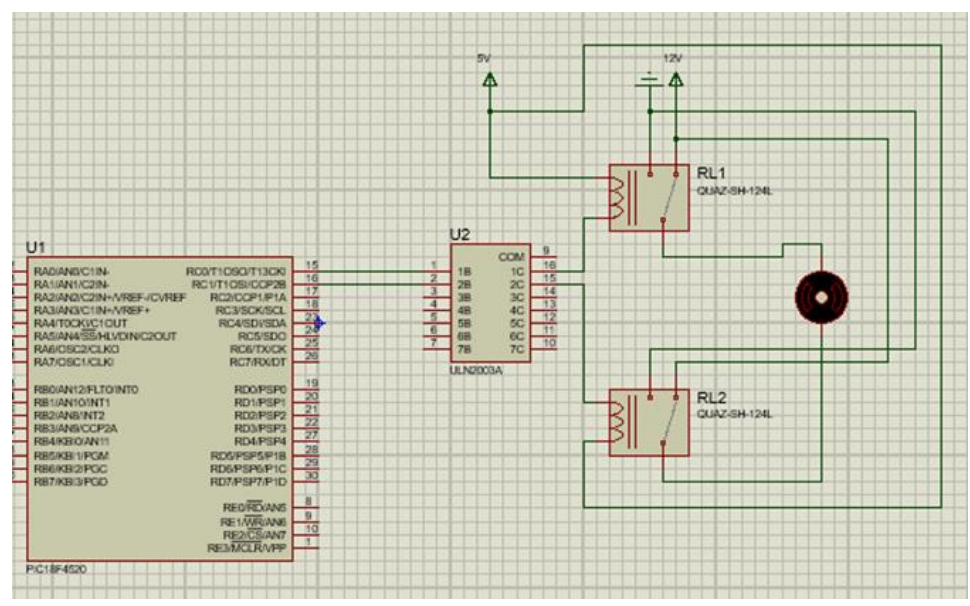

Figure 4. Schematic Diagram of the PIC Microcontroller Interfaced with the DC Motor.

\subsubsection{Level Sensor and Microcontroller}

The level sensor in this project is responsible for monitoring the fill level of the waste bin. This was carried out by interfacing the two LDR sensors directly facing two LEDs in the waste container to the microcontroller through LM358 OPAMP. Both LDR sensors are interfaced to LM358 OPAMP that gives feedback to the microcontroller about the current fill level of the container. The LM358 OPAMP is connected to pin 19(RDO/PSPO) and pin 20(RD1/PSP1) of the microcontroller. When the ray of light from the LED falling on the LDR sensor is being blocked completely by the waste in the waste bin, the LM358 OPAMP will send a high state signal to the microcontroller so as to enable it activate the GSM module. Figure 5 is the schematic diagram of how the LDR was interfaced with the microcontroller to perform this function.

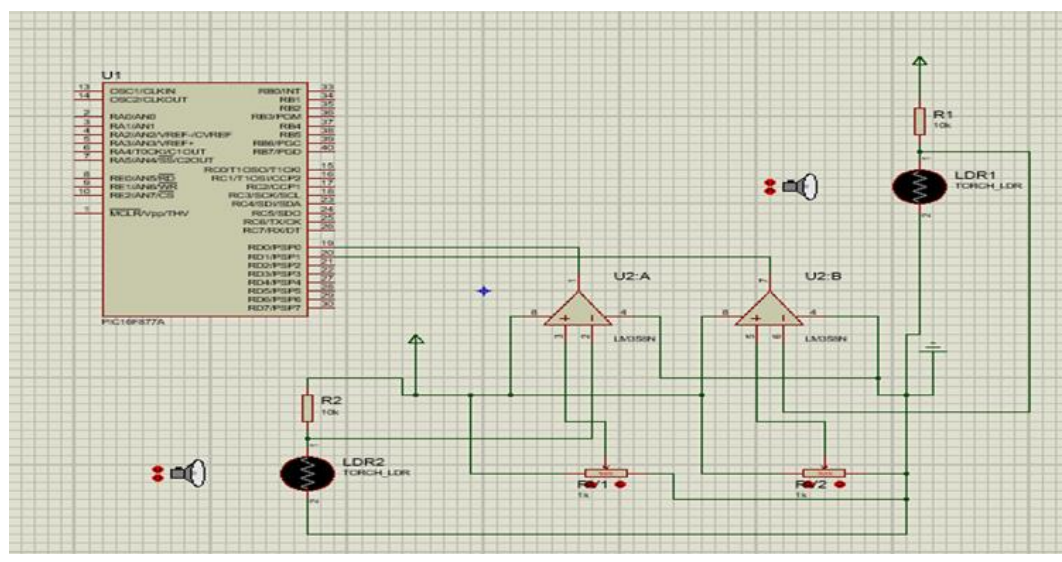

Figure 5. Schematic Diagram of the Microcontroller Interfaced with the two LDR Sensors. 


\subsubsection{LCD and Microcontroller}

The LCD panel used in this work is a 16x2 alphanumeric display type. This was interfaced directly to the microcontroller by connecting it to pin 36 (RB3/PGM), pin 35 (RB2), pin 34 (RB1), pin 33 (RBO/INT), pin 37 (RB4) and pin 38 (RB5) of the microcontroller. The LCD panel acts as a graphical interface between the smart waste bin and the human intending to dispose a waste in the waste bin. During implementation of the work, we programmed the LCD panel to function at two states which are:

- Empty State and,

- $\quad$ Filled-up State

When it is in the empty state, it is programmed to display that the bin is still empty and therefore has room to contain more waste in the trash system. The filled-up state comes up when the LM358 OP AMP which monitors the fill level of the container sends a high state signal to the microcontroller indicating that the waste container is full. Figure 6 is the schematic diagram showing how the LCD was interfaced with the microcontroller while Figure 7 shows the complete circuit diagram. Also, Figure 8 shows the flow chart of the smart solid waste collection system.

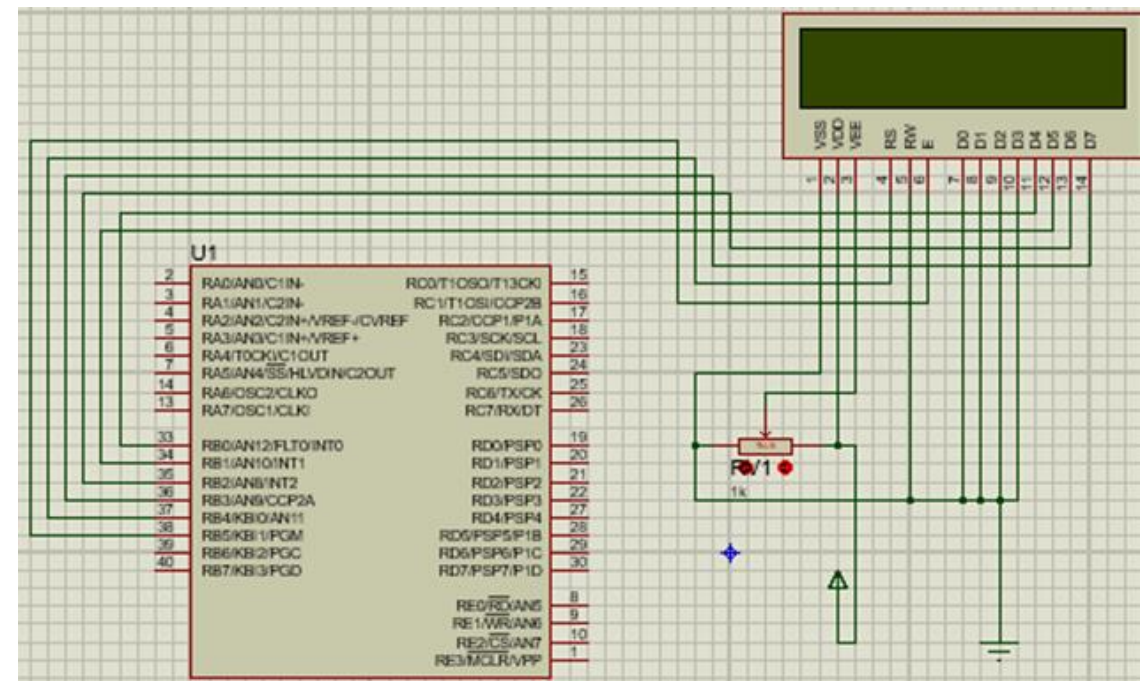

Figure 6. Schematic Diagram Showing how the LCD was Interfaced with the Microcontroller. 


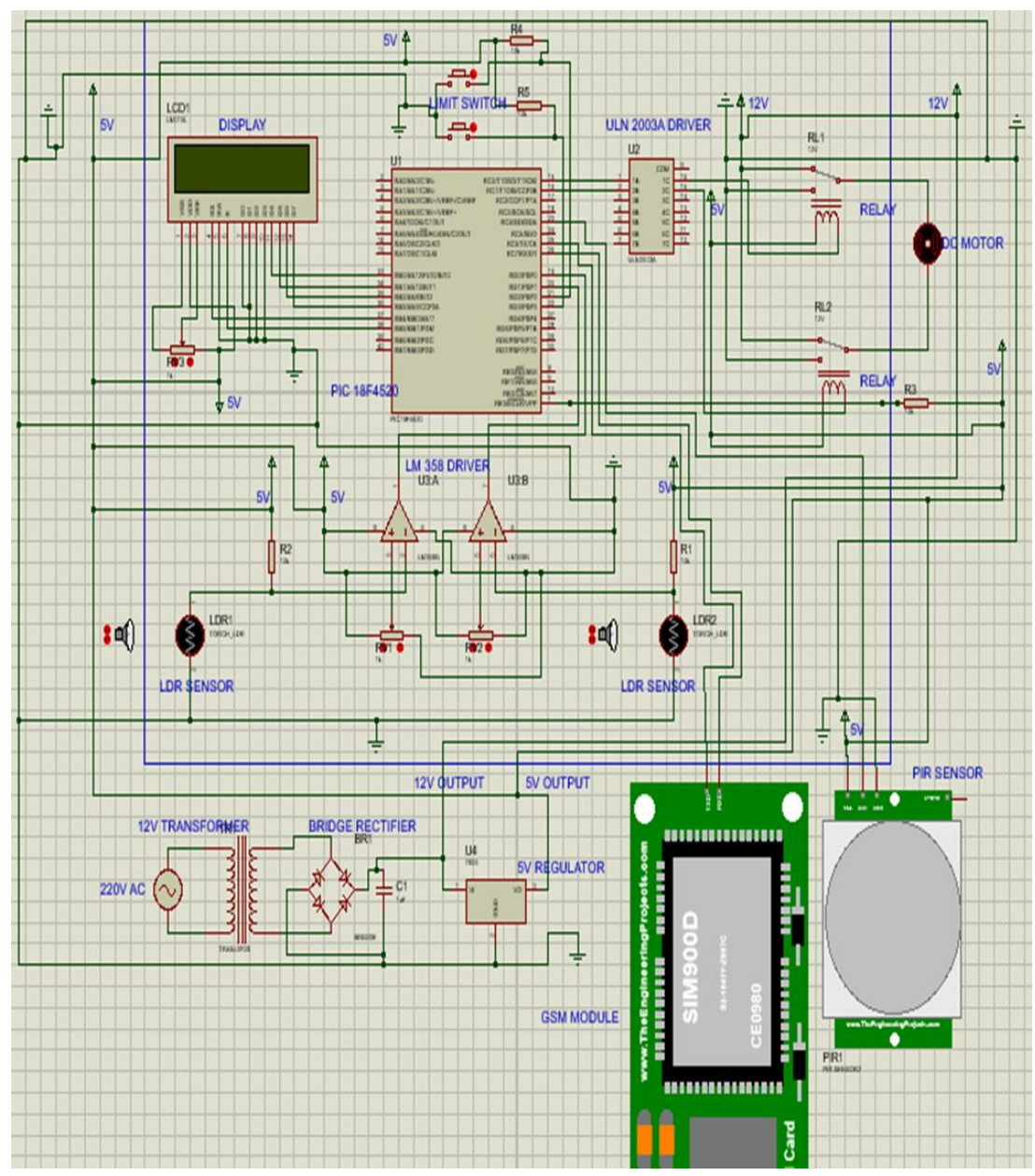

Figure 7. Circuit Schematic Diagram of the Smart Waste Collection System.

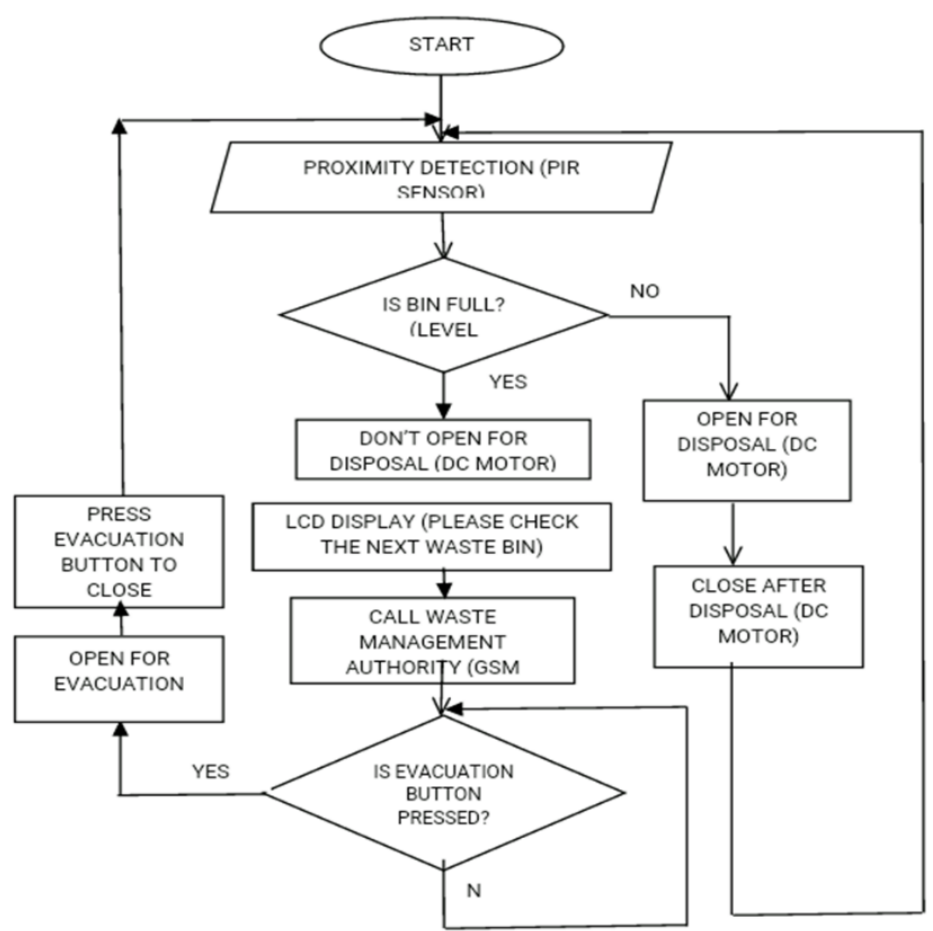

Figure 8. Flowchart of the Smart Solid Waste Collection System. 


\section{Results and Discussion}

\subsection{Implementing the Output Unit of the System}

The output unit of the system in this project is the LCD display, this acts as the user interface between the user and the system as a whole, it displays the current status of the system and tells the user about the next phase of instruction that is being carried out by the controller. Figures 9 and 10 are the simulation and real-time images of the LCD displaying the current status of the system.

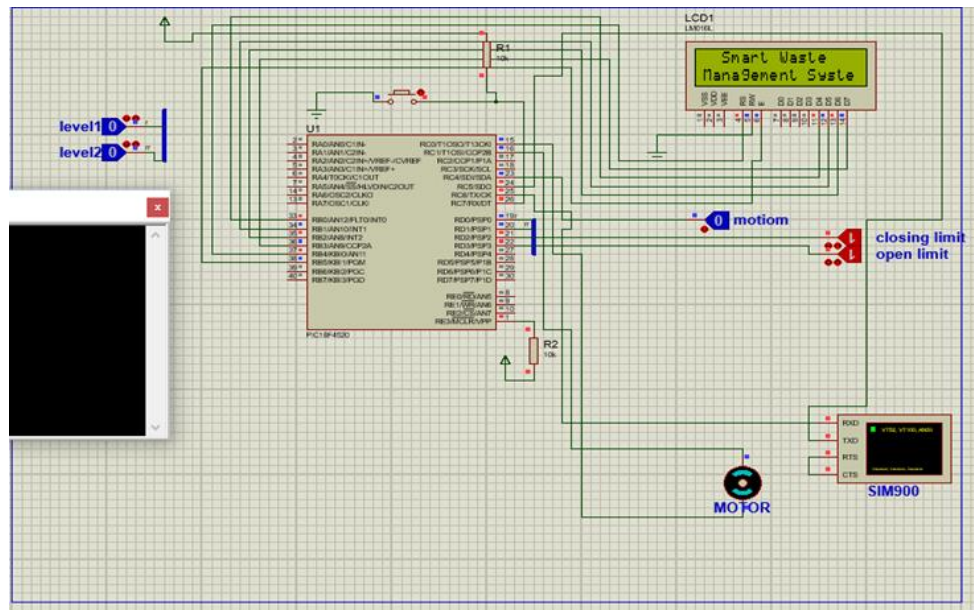

Figure 9. Proteus Simulation of the System Showing its Initialization Mode.

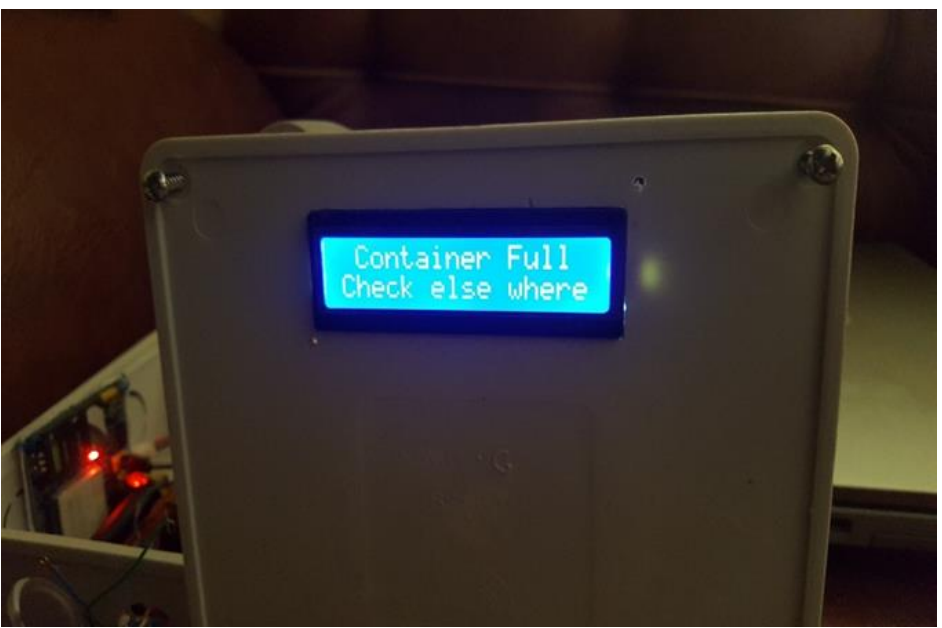

Figure 10. Image View of the Output Unit Displaying the Current Status of the System.

\subsection{Implementing the Sensing Unit}

During the implementation of this unit, we tested the major components that make up the unit, which includes the PIR sensor and LDR device. During the design of this work, the sensors were first simulated on Proteus by representing them with logic states. These states determine the exact behavior of the system and the general ideology involved in running the system. Figures 11, 12 and 13 are images showing the different responses of the system when different states are assigned to the sensors. When a high state is being assigned to the motion sensor. The result of the output above was gotten when the PIR sensor was activated on detection of motion. In Figure 122, the current reaction of the system was as a result of deactivation of the PIR sensor, i.e., a low state was assigned to the sensor. This was achieved physically by stopping motion in front of the PIR sensor. 
Figure 133 shows the current state of the system, this was achieved when a low state was assigned to both LDR devices acting as level sensors in the waste container, this condition can only occur when the waste bin is full.

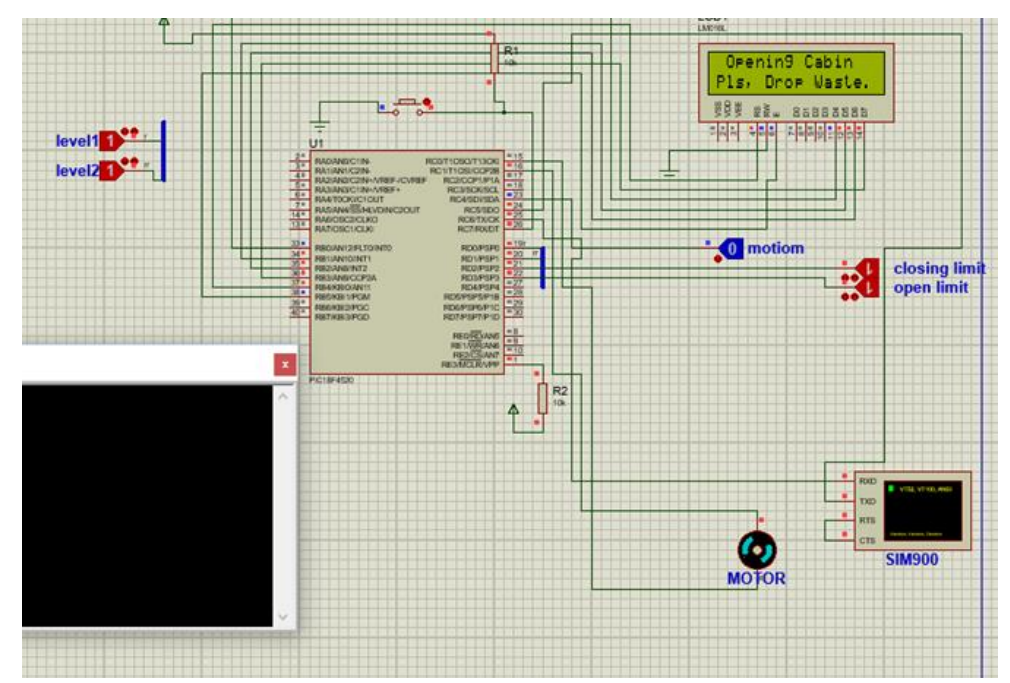

Figure 11. Circuit Simulations Showing the Reaction of the System.

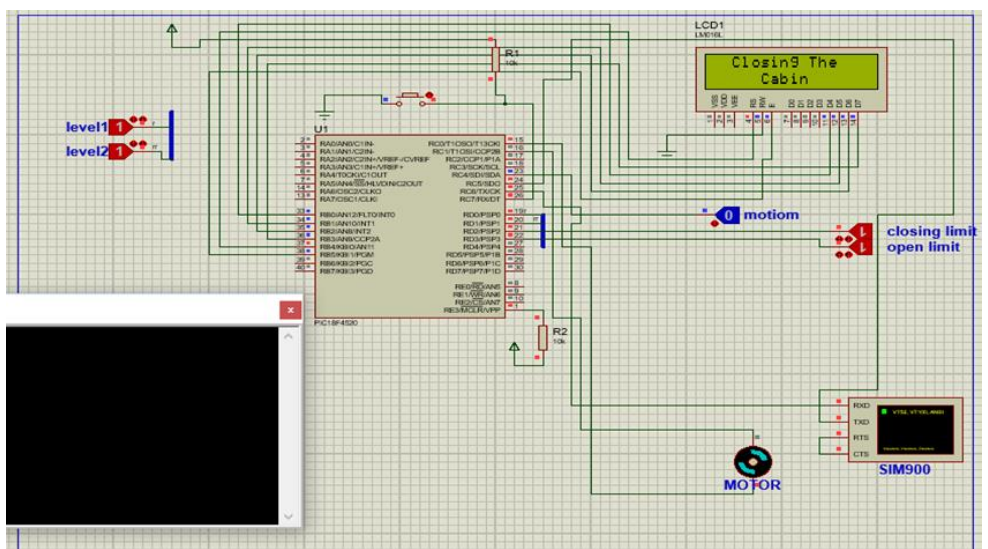

Figure 12. Circuit Simulation of the System Showing its Current Status.

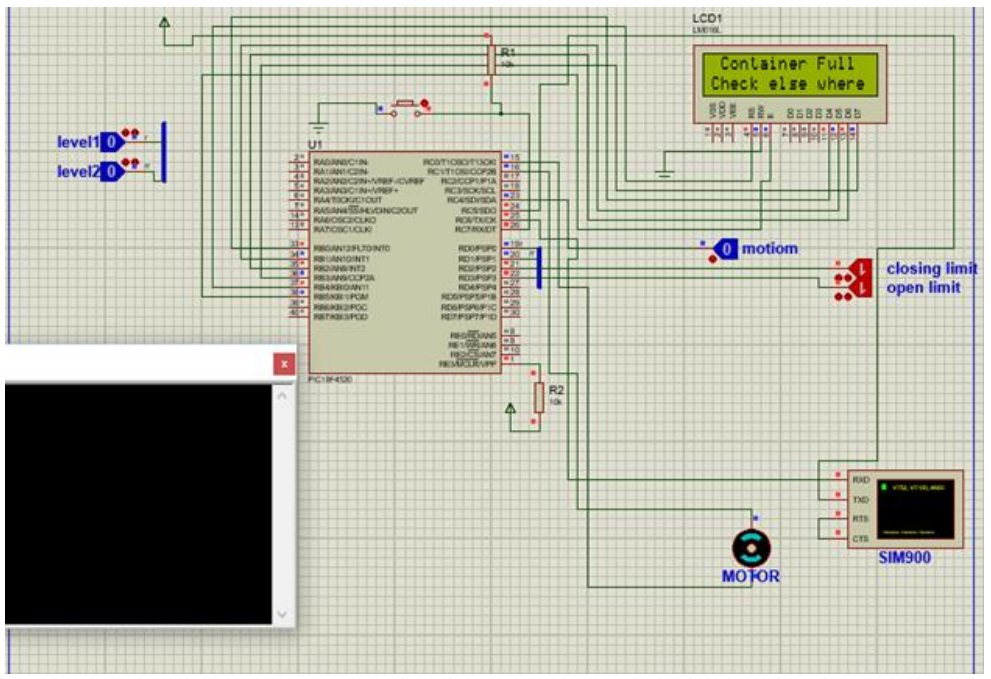

Figure 13. Circuit Simulation showing the Current Status of the System. 


\subsection{Implementing the SMS Sending unit using the GSM Module}

The reaction of this unit was as a result of the low state assigned to the level sensor when the waste bin was filled up. The microcontroller sends a high state to activate the GSM module which is connected to its serial port. The GSM module sends a message across to waste authorities notifying them that the waste bin is filled and is ready for evacuation. Figure 144 is a circuit simulation that shows the serial transmitter displaying the SMS text that is to be sent to the waste authority.

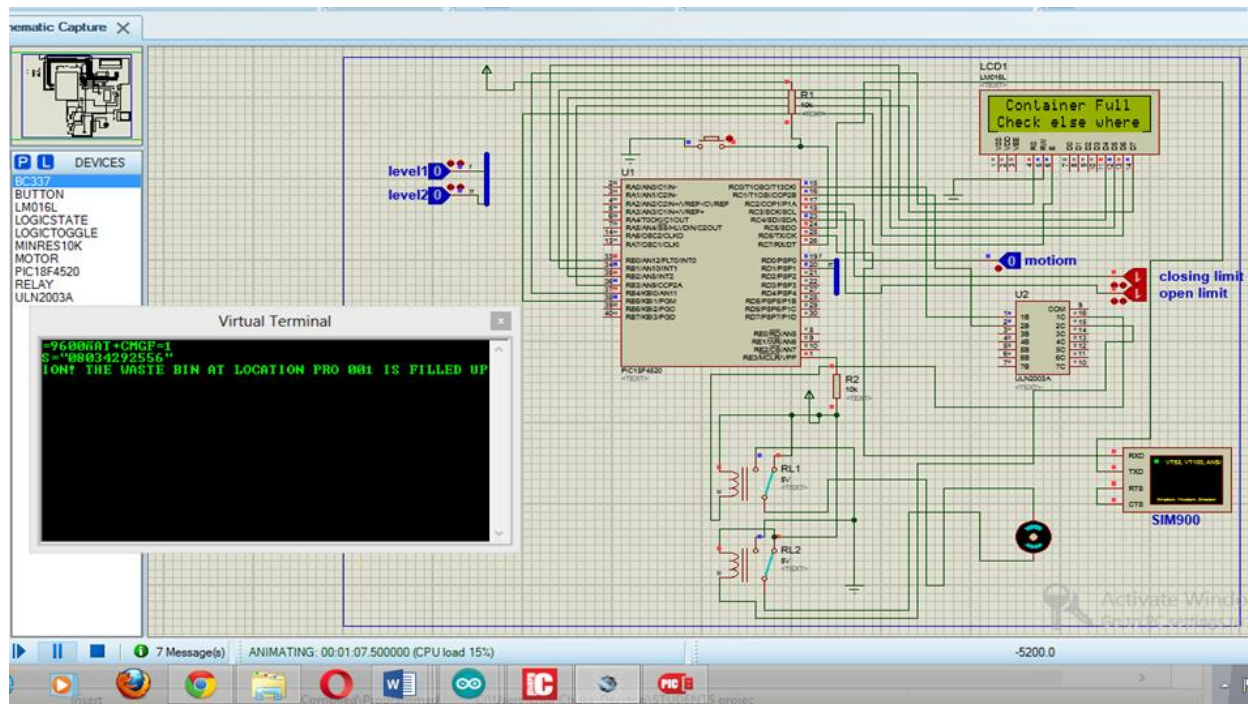

Figure 14. Circuit Simulation of the Current Status of the System.

\subsection{System Testing}

After the units of the system were integrated together, an open-circuit test was carried out where the individual connections of the system were tested to ensure continuity. Satisfied with the continuity test, the power supply test was carried out to ensure that the power requirements of the various branches were met. The functionality of the individual sensors and components were also tested. The testing of the application was not done at once after it was completed, rather each unit of the application was tested individually. The second unit was not tested until the first unit gave the expected result and until it was working according to the necessity of the application. After all of the units were working correctly, the units were kept together and then the whole system was developed and tested. It was easy to figure out the bugs and the problem of the system as the behavior of each unit was known while testing it. It would be impossible to figure out the problems and the bugs in the system if the system was developed and tested after it was completed. Table 1 shows the testing results. 
Table 1. Test Result of the System.

\begin{tabular}{|c|c|c|c|c|}
\hline Unit & Logic State & $\begin{array}{l}\text { Microcontroller Ongoing } \\
\text { Operation }\end{array}$ & $\begin{array}{l}\text { Waste Container } \\
\text { Status }\end{array}$ & $\begin{array}{l}\text { Output of the System as Dis- } \\
\text { played by the LCD Panel }\end{array}$ \\
\hline Motion sensing & Low & & & SSWM system in operation \\
\hline $\begin{array}{l}\text { Motion } \\
\text { Sensing }\end{array}$ & High & $\begin{array}{l}\text { Checking fill level of waste } \\
\text { container }\end{array}$ & Not full & Opening for waste disposal \\
\hline Motion sensing & High & $\begin{array}{l}\text { Checking fill level of waste } \\
\text { container }\end{array}$ & Full & Container full check elsewhere \\
\hline $\begin{array}{l}\text { Level sensing } \\
\text { (both LDR) }\end{array}$ & High & Activating DC motor & Not full & Opening for waste disposal \\
\hline $\begin{array}{l}\text { Level sensing } \\
\text { (both LDR) }\end{array}$ & Low & Activating GSM module & Full & Container full check elsewhere \\
\hline GSM module & High & SMS sending in progress & Full & Waiting for waste evacuation \\
\hline $\begin{array}{l}\text { Evacuation but- } \\
\text { ton }\end{array}$ & Low & Activating DC motor & Full & Opening for waste evacuation \\
\hline $\begin{array}{l}\text { Evacuation but- } \\
\text { ton }\end{array}$ & Low & Activating DC motor & Empty & Closing cabin \\
\hline
\end{tabular}

Table 2. Latency experienced at every successful waste bin opening.

\begin{tabular}{cc}
\hline Number of Trials (N) & Waste Bin Latency (sec) \\
\hline 0 & 0 \\
1 & 05 \\
2 & 05 \\
3 & 07 \\
4 & 05 \\
5 & 06 \\
6 & 07 \\
7 & 05 \\
8 & 05 \\
9 & 06 \\
10 & 05 \\
Total average & 5.6 \\
\hline
\end{tabular}




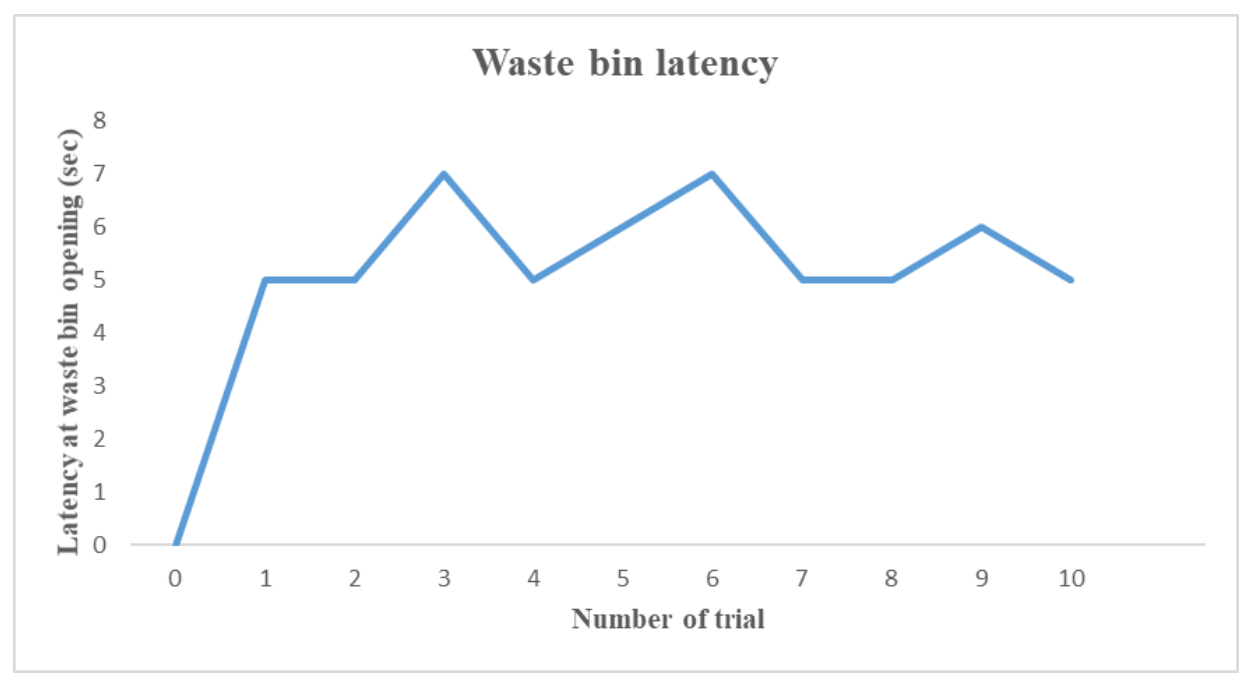

Figure 15. The Graphical Representation of the Latency Experienced at every Successful Waste Bin Opening.

\subsection{System Availability on Demand and Latency Experienced at Every Successful Waste Bin Opening of the System}

The service availability on demand was ascertained by switching $\mathrm{ON}$ and accessing the functionalities of the system. This was done ten (10) successive times and each of them was successful. The latency (the time delay for the waste bin to be fully opened and ready for use) of the system was also noted as shown in Table 2. It can be seen that its average latency is $5.6 \mathrm{sec}$, giving that the maximum allowable latency for such a system should be 20 seconds, it means that the latency of the existing system is $28.0 \%$ of the maximum allowable latency.

\subsection{Performance Evaluation of The Electronic Waste Bin System}

The developed electronic waste bin system was evaluated by comparing its availability on demand with that of the existing waste bin system. Table 2 shows the availability of the electronic waste bin system. It can be seen that the system success rate which is a function of the system's availability is the same as the existing system. This means that the intelligent features incorporated in this system had zero (0) impact on success rate or system availability.

On the other hand, the Figure 155 shows the graphical representation of the latency experienced at every successful waste bin opening, it can be seen that the automation introduced an average delay of 5.6 seconds $(28.0 \%)$ into the electronic waste bin system.

Now, environmental safety and availability are the key performance indicators for evaluating environmental waste bin system. In this system, the safety of the environment where it is deployed is of great importance, while availability which is measured by latency of the system, is not critical as compared to environmental safety.

\section{Conclusions}

The automatic waste collection process is a step that is taken in order to reduce the hardship of manual collection and detection of wastes in an automatic manner. The purpose of designing the automatic collection system is in terms of its efficiency and time saving nature when compared to the already existing one. In the currently employed method the concerned municipal worker has to locate the bins manually and check the status of the trash bin. This is a very complex, tasking and a time-consuming process. Hence, there is an immediate need to automate the process of waste collection to reduce the human effort and therefore reduces the cost of the whole process. 
As a result of the above needs a model for electronic waste collection system leveraging on wireless communication for effective waste disposal was developed, which automatically manages waste collection and disposal, eliminates the need of regular checking of the waste bin as well as spreading of diseases as a result of the continuous opening of the traditional waste bin. This was actually realized by the incorporation of remote reporting device to the host controller so as to alert relevant authority when a particular waste bin is full.

This system can be deployed anywhere effective waste collection is required. The reduced cost of the entire process makes it affordable.

Hence, the entire method used for the detection and collection of waste makes the system efficient and intelligent.

\section{References}

[1] Ivey, K. N., Muth, A., Arnold, J., King, F. W., Yeh, R. F., Fish, J. E., Hsiao, E. C., Schwartz, R. J., Conklin, B. R., Bernstein, H. S., and Srivastava, D. (2008). Microrna regulation of cell lineages in mouse and human embryonic stem cells, Cell Stem Cell, 2: 219-229.

[2] Chen, J. F., Mandel, E. M., Thomson, M., Wu, Q., Callis, T. E., Hammond, S. M., Conlon, F. L. and Wang, D. Z. (2008). Theroleofmicrorna-1 and microrna-133 in skeletal muscle proliferation and differentiation. Natural Genetics, 38:228-233

[3] Boileau, H. and Bjork, H. (2006). Comparing household waste treatment policies between two medium size cities: Boras (sweden) and chambery (france)," in Proceedings of the 7th World Congress on Recovery, Recycling and Re-integration. Available: http://csp.eworlding.com/3r/congress/manu pdf/420.pdf.

[4] Ramesh, S. N., Shreenivas, P. N, Akshay, N., and Akhil, S. N, (2016). A study on Internet of Things Enabled Smart Store. Institute of Integrative Omics and applied Biotechnology (IIOABJ), 7 (2): 61-67

[5] Shyamala, S. C. and Satpal, S. (2016). "Smart Waste Management System”. International Journal of Scientific Development and Research (IJSDR), 2, (3); 45- 78. Available at www.ijsdr.org.

[6] Srikanth, S. V., Pramod, K. D., Tapas, Patil, S. M., and Sarat, C. (2017). Design and implementation of a prototype smart parking (spark) system using wireless sensor networks. International Conference on Advanced Information Networking and Applications Workshops, WAINA 401-406.

[7] Faccio, M. Persona, A. and Zanin, G. (2011). "Waste collection multi objective model with real time, traceability data”, science direct, Waste Management, 31(12):2391-2405

[8] Kai, Y., Junmei, Z, Wenbin, L. Liu, Y., Linand, G., and Huixia, X. (2011). Weighing System of Fruit-Transportation Gyrocar Based on ARM," Third International Conference on Measuring Technology and Mechatronics Automation (ICMTMA), Shangshai, 1146-1149.

[9] Mohd, N.H., Theng, L.C., Mizanur, (2016). Radio Frequency Identification (RFID). for the Business of Waste Management, "Smart Garbage Collection System in Residential Area". www.falkensecurenetworks.com. 